\title{
A pedagogy of belonging: troubling encounters with ethnic and religious difference
}

\author{
Kathryn Edgeworth (1) \& Ninetta Santoro (2) \\ (1) Faculty of Education, University of Tasmania, Launceston, Australia \\ (2) Faculty of Humanities and Social Sciences, University of Strathclyde, Glasgow, \\ Scotland
}

Dr Kathryn Edgeworth, Faculty of Education, University of Tasmania, Locked Bag 1307, Launceston, Tasmania, 7250, Australia.

Kathryn.Edgeworth@utas.edu.au

Understanding the construction of belonging and how unbelonging might be troubled, is critical work. For schools in many parts of the world, one of the many challenges of globalisation is the task of teaching with, and for ethnic and cultural diversity. In this paper we examine the exclusionary practices of teaching that construct ethnic and religious minority students in states of unbelonging. These practices are due, in part, to teachers' failure to really know their students. Alongside this argument, we examine discourses of belonging in rural schools that speak to possibilities for everyday place-sharing for ethnic and religious minority students. Simple and common moments of mutual recognition and understanding speak to the possibilities for belonging that are opened up in everyday relations of knowing. We consider the implications of these ideas for teachers and teacher education in what is framed as a 'pedagogy of belonging'.

Keywords: teacher education; ethnicity; rural education

\section{Discourses and practices of belonging and unbelonging in rural schools}

Belonging has been described as "a state of social inclusion" (Sibley, 2006, p. 401) and as "the mutual recognition of the other" (Noble \& Poynting, 2010, p. 491). It is a term connected to notions of 'boundary', where to belong, is to exist within the bounds of 
accepted difference. To 'not belong' is to experience exclusion on the basis of transgressing these same boundaries. Poststructuralists stress the discursive production of belonging, where states of belonging and unbelonging are created in discourses about 'who-we-are and who-we-are-not' (Arber, 2008). In such a configuration of belonging, privileged and legitimised forms of knowledge and power determine belonging and define the boundaries of normativity. Judith Butler's (1997) work on performativity, in particular her engagement with Foucault's theories of power and knowledge, highlight the way discourses 'form the objects of which they speak' and have productive capacity. Such regimes of understanding have implications for how students experience belonging in schools. Put simply, discourses of schooling 'make' what they 'name' as they circulate in social and cultural practice. Teacher 'talk' about 'normal' and 'acceptable' ways of being can construct ethnic and religious minority students in states of unbelonging, a point to which we return later in this article.

Understanding the construction of belonging, and how unbelonging might be troubled, is critical work. For schools in many parts of the world, one of the many challenges of globalisation is the task of teaching with, and for ethnic and cultural diversity. The flow of people across nations as a result of war, political unrest, and changing labour and education markets, means that school populations that were once relatively homogenous are now experiencing increased ethnic and cultural diversity (Santoro, 2009). Yet, research into schooling in intercultural contexts suggests that improved educational outcomes for ethnic and cultural minority students remain elusive (Keddie, 2012a, 2012b). Teachers continue to be ill-prepared to teach for belonging (Lander, 2011), despite policy and research initiatives aimed at improving their knowledge of their students. Resistance to the take up of culturally responsive pedagogies continues to constitute an area of concern (Santoro, 2013; Mills \& 
Ballantyne, 2010), while initiatives aimed at interrogating and unsettling normative constructions of identity in schools are reported to have been met with opposition (Youdell, 2011). As a consequence, discourses of unbelonging continue to prevail in schools, thereby challenging teacher educators to continue researching ways of doing schooling differently.

The research project on which this paper is based was concerned with rural schooling. This focus recognises that global and national debates about belonging and unbelonging inevitably play out on rural soil. Debates over immigration, interculturalism, terrorism, asylum seekers and refugees, for example, signify something of the relationship citizens have with 'self and others'. It becomes inevitable that these tensions, and the logic that underpins them, are felt in rural communities, and subsequently, in rural schools. As places are more closely connected by changing geopolitical relations, so associations in the everyday are impacted (Pain \& Smith, 2008). Schools, as sites of cultural interplay, are key to understanding how rural populations have been transformed by ethnic minority populations, as well as how these persons are constituted by rural relations.

In this paper we examine the exclusionary practices of teaching that construct ethnic and religious minority students in states of unbelonging. These practices are due, in part, to teachers' failure to really know their students. Alongside this argument, we examine discourses of belonging in rural schools that speak to possibilities for everyday place-sharing for ethnic and religious minority students. In this sense, we do not suggest that only binary states of belonging and unbelonging circulate in schools. Simple and common moments of mutual recognition and understanding speak to the possibilities for belonging that are opened up in everyday relations of knowing. These ideas are taken up in this article in what is framed as a 'pedagogy of belonging'. This strategy for 
culturally responsive teaching is explored in this article through an examination of the lived experiences of two ethnic and religious minority students and their relationship with notions of belonging and unbelonging. We draw on data from an ethnographic study that investigated the schooling experiences of ethnic minority, Muslim and refugee young people in rural New South Wales, Australia. We present vignettes of interview data and observation data to illustrate how teachers' talk and practice can lead to the construction of states of belonging and unbelonging for ethnic and religious minority students. We highlight the role of teachers in making viable and non-viable, raced, nationed and religioned bodies in education and explore pedagogical possibilities for educators seeking to disturb these injustices in schooling. In particular, we consider the role of a 'pedagogy of belonging' in troubling schooling exclusions. We conclude by considering the implications for teacher education.

\section{The study}

The study examined the educational inclusions and exclusions the students experienced as a result of the privileging of normative knowledges and practices. After obtaining university ethics approval, volunteers were sought from three rural schools. Six students consented to participate. They ranged in age from 15 to 20 and came from culturally and linguistically diverse backgrounds (CALD) ${ }^{1}$.

\footnotetext{
${ }^{1}$ Inglis (2009) writes that the term 'culturally and linguistically diverse' has commonly replaced the term 'nonEnglish speaking backgrounds' in official educational usage in Australia. We take up the use of CALD in this study to refer to students from Language Backgrounds Other Than English (LBOTE) (the category schools used to record CALD students at the time of this study), as well as to refer to students who have English as a first language who come from culturally and linguistically diverse backgrounds.
} 
In this article we draw on data from two of the students; Saeed and Hanif ${ }^{2}$. Hanif is a 16 year old Muslim refugee from Afghanistan who has lived in Australia for 13 years. Saeed is a 16 year old Australian-born Muslim of Pakistani heritage. Hanif lives in a large regional centre (population, 30,000 persons) some six hours drive from a capital city, and Saeed in a small rural town of some 3,000 people, four hour's drive from Sydney. Of the approximate 300 students enrolled at Springville High School where Saeed is a student, five students are from Language Backgrounds Other Than English. At Gundah High School, where Hanif is a student, of the 800 students enrolled, approximately 20 students are from Language Backgrounds Other Than English. Six of these students are refugees from Afghanistan. Both Gundah and Springville high schools are notable for a newly diverse ethnic composition as a result of shifting global populations. While the populations of each of these rural towns is constitutive of only very small numbers of immigrants and refugees, the confined nature and size of the towns means that ethnic and religious minority residents are often highly visible. Students too, are frequently highly visible members of their schools.

Fieldwork was conducted over a period of one school year. Approximately one school term (which amounts to a period of 10-13 weeks) was spent in each school setting. Approximately twenty observations of each student occurred in the playground and in other parts of the school, as the school day dictated. The research objective was to simply follow the student to observe how they 'do' school, and to record observations in a field notebook. Data collection and analysis methods informed by poststructuralist theoretical frames acknowledge that analysis takes place from the researcher's first moments in the field as he or she makes choices about where to look and what/whom to look at (or ignore), and how to make sense of data in terms of the subjectivities taken up

\footnotetext{
${ }^{2}$ In order to protect anonymity, pseudonyms are used for participants and for school and place names.
} 
(or not) and the discursive frames employed (or eschewed) (Youdell, 2006). The processes that see data selectively reproduced in this study are mediated by a recognition of the researchers' own discursive capacities - "the discourse that I see and name" (Youdell, 2006), p. 513). In this sense, in recording and offering data, we present compelling moments from the field that represent how we see knowledges and subjects as constituted. This privileging of some data over others is enacted with the intention of opening up regimes of truth to questioning, particularly as these truths produce inclusions and exclusions in schooling (Edgeworth, 2014). In the words of Youdell (2006), the narratives we have selected "do not contain, expose or reflect any universal truth", but they do "resonate" (p. 513).

One semi-structured in-depth interview was conducted with individual students and lasted between thirty minutes and one hour. Interviews took place in a quiet space on school grounds, with only the student and researcher present, usually in an area like a study room in the school library or an empty classroom. Interviews were guided by a set of questions that sought to capture the participants' background, along with their perspective on being an ethnic minority, Muslim and/or refugee student in a rural school and rural community. Specific questions related to the following: what it is like to be of a particular ethnicity/religion at school; what interest others take in their ethnic background; and how teachers and students at the school respond to students who come from an ethnic, religious, cultural or linguistic background different from their own. The students were also questioned about differences between the city and rural areas as they had experienced them, and were asked to reflect on how people from other cultures in their town fitted in. Students were sometimes asked to reflect on events observed by the researcher in the classroom, or on aspects of school culture as this might affect them. 
In what follows, we present vignettes of data from interviews with, and observations of, Hanif and Saeed in order to highlight how teachers' knowledge of Others creates ethnic and religious minority students in states of unbelonging. Vignettes are drawn from transcripts of interviews conducted with students in schools, as well as from fieldnotes. Where we present fieldnotes in a vignette, we do so in the form of a script. In this sense, the data is self-consciously presented as a performance (Goldstein, 2008). We do this to highlight the discursive nature of the text, as well as to facilitate further discursive possibilities (Youdell, 2006).

First, we examine Saeed's schooling experience to illustrate how discourses of belonging and unbelonging circulate in schooling environments. Understanding how teachers position students in states of unbelonging through teacher-talk has implications for understanding schooling inclusions and exclusions. We then take up the narrative of Hanif to highlight teachers' practice in relation to the creation of states of unbelonging. We pay particular attention to how teachers' knowledge of students affects how students are framed and are able to experience learning.

\section{Discourses of exclusion: Saeed}

In the following vignette, in the context of a playground discussion at Springville High School, we explore how teacher-talk, a form of discursive practice, impacts on 'who' a student can be, and the limits of their belonging. de Certeau's (1984) argument that stories work to mark out boundaries of belonging is taken up in this vignette. We use de Certeau's theory of spatial legislation to illustrate the way talk is employed at Springville High to constitute students as particular sorts of raced, nationed and religioned subjects, with implications for how students 'do' school and 'who' a subject can be within the schooling environment. 
Table 1. Vignette One: How to be 'okay' at Springville High School

The teacher (male, White, 50s) on playground duty is showing me Saeed's "haunts", as he calls them. That is, the places where Saeed and his friends commonly "hang out" in the Springville High school yard. Mr James tells me that the students are "territorial", that they will not be too hard to find because they never venture too far from their usual hiding places.

Here they are, next to the demountables - Saeed and a group of about six friends who are mostly male. Mr James describes Saeed's best friend, Skipper, as your typical "fat Aussie bloke". His other "best mate", Paul, like Skipper, is from a farming family. $\mathrm{Mr}$ James tells me that both boys are into pig shooting1 and all things farming. Mr James says that he gets the feeling that in choosing these friends, Saeed is "trying to be more Australian than the Australians"; that Saeed's Australian accent seems to get broader when he is trying to fit in sitting in class next to these boys.

Mr James suggests that while Saeed and his brothers openly identify as Muslim at Springville High, they are not "pro-active" about their identity. He says that the brothers do not want to stand out and are not "pushing any limits". He suggests that if the boys had a sister at the school who chose to veil, for example, the reaction from the school community to such an action would be "like a Martian landing", and that such an event would test Saeed and his brothers' place in the Springville High community. Mr James suggests that Springville students openly refer to Muslim students in derogatory ways, using terms like "towelheads", but if it is pointed out to the same students that Saeed and his brothers are Muslim, these same students will say “Oh, they're okay”. (Researcher Fieldnotes) 
Butler's (1997) notion of performativity suggests that persons are not simply described as subjects, but are also produced and made through naming practices. Butler argues that language has power, "not only to name, but also in some sense to perform", where "the word ... enacts what it names" (p. 43). When Mr James suggests that Saeed is "trying to be more Australian than the Australians", he performatively places Saeed outside of what it means to be a 'real' Australian, casting him as 'different' in this rural place, with implications for how Saeed belongs and how he is positioned to receive schooling. Such 'storytelling' is commonplace at Springville High School, with discursive performatives routinely enacted and shaping the way that 'Australianness' is understood and constituted in the school environment. Such a climate has implications for how staff and students recognise themselves as teachers and learners. In turn, it influences how educational belonging and unbelonging is shaped. de Certeau (1984) suggests that stories are often told in order to map spatial boundaries, to delimit who rightfully belongs in a geographical area and who belongs outside it. He writes:

the story plays a decisive role. It 'describes', to be sure. But 'every description is more than a fixation', it is 'a culturally creative act'. It even has a distributive power and performative force (it does what it says ... it founds spaces. (p. 123)

Mr James' narrative about Saeed and his friends functions, as de Certeau suggests, to performatively mark the territory by which belonging is determined. de Certeau suggests that:

The narration is 'established' on the basis of 'primary' stories ... stories that already have the function of spatial legislation since they determine rights and divide up lands by 'acts' or discourses about actions. (p. 122)

Mr James' 'spatial legislation' about what it means to be a 'legitimate' Australian, based on what appears to be narrative hyperbole about the relative strength of Saeed's 
accent and his choice of friends, functions discursively to mark Springville as White territory where to be (ethnically and religiously) Other, is to sit outside the bounds of what it means to gain acceptance and belonging.

Hage (1998), in a critique of 'tolerant' multiculturalism and its unexamined centering of White privilege in Australia, suggests that persons adopt the characteristics and cultural styles (or national character and culture) of the dominant cultural group in order to acquire national belonging: "looks, accent, demeanour, taste, nationally valued social and cultural preferences and behaviour, etc" (p. 53). However, those persons who lack the physical characteristics of the dominant national 'type' - such as White skin or blonde hair - will necessarily have a lesser claim to national belonging than those whose 'entitlement' is determined by these characteristics. This model of understanding allows us to comprehend the way Saeed's ethnicity is constructed by his teacher. Although Saeed was born to Australian nationality and has acquired, and exhibits at Springville High, the nation's dominant cultural and linguistic traits, his body morphology is deemed to render him outside of what it means to be 'genuinely' Australian. Regardless of the ways in which he has acquired belonging, Saeed's recognition as a 'legitimate' Australian subject remains tenuous as a result of his ethnicity. He is regarded differently by his teacher because his ethnic status gives him less belonging than other Australian born citizens. He is situated beyond the bounds of what it means to be a 'natural' Australian and a 'genuine' Springville High School student and learner.

Allard and Santoro (2006) and Santoro (2009) argue that Anglo-Australian student teachers commonly fail to recognise their own ethnicity, instead understanding ethnicity as a trait of Others. Therefore, students of ethnic and religious difference are constructed outside the normative discourses of the mainstream, where to be 'only 
Australian' is understood as being a 'real' Australian" (Allard and Santoro, 2006).

Despite Saeed's quintessentially (rural) Australian interests and his Australian friends, his failure to be White sees him constituted as non-Australian by his teacher. He is marked as not 'really' Australian. He is just trying to be the 'real deal' - he is just trying because he is not White, and hence, is marked as different, and belongs differently, within the school. This production of unbelonging has potential implications for how Saeed is positioned to receive schooling.

While Mr James suggests that Saeed might be considered an unobtrusive presence in the school in the sense that he is not 'pushing any limits' or being "proactive" about his ethnic or religious identity, Saeed nevertheless stands out against the discursive frame of the normative student at Springville High. He is recognised by many as a Muslim at Springville High School. Mr James' remark that Saeed is not pushing the boundaries of religious tolerance in relation to his Muslim identity suggests that Saeed, in acknowledging the limits of acceptance of his religious faith by the dominant culture, downplays his difference. As Hage (1998) writes about tolerance and acceptance of difference by members of the hegemonic mainstream:

The power to tolerate is ... the power to position the other as an object within a space that one considers one's own, within limits one feels legitimately capable of setting. (p. 90)

Those in a dominated position do not tolerate, they just endure. (p. 88)

At Springville High, the limits of tolerance are discursively maintained by the dominant White majority. The limits of this acceptance are most in evidence in $\mathrm{Mr}$ James' remarks regarding the acceptability of a veiled Muslim student at Springville High. The veil, it is suggested, would sit outside the bounds of tolerance. It would be, Mr James suggests, "like a Martian landing". To this end, as Martino and Rezai-Rashti 
(2008, p.418) write: "the veil [is] a signifier of an essentialized or monolithic Muslim identity (See Rezai-Rashti, 1999)” (p. 418). It constructs the wearer in simple binary terms as a racialised Other, creating a highly visible reminder of the tensions existing between the West and Islam, or as Martino and Rezai-Rashti (2008, p.418) suggest, constructs an anti-Muslim discourse around the wearer: "The Muslim subject is not like 'us' and, hence, does not subscribe to our democratic and supposedly enlightened values (Said, 2003, p. xx)". In Springville, a student who chose to veil would interrupt the local and substantive conditions of Islam as represented by Saeed, and would bring into play an "imagined" hegemonic, essentialised version of Islam, where circulating "discourses about veiling ... confirm ... truths about ... Islam" (Martino and RezaiRashti, 2008, p. 419). Such 'truths' are in contrast to the unobtrusive ways in which Saeed performs his Muslim self at Springville and suggest the contingent nature of the religious acceptance accorded Saeed. As a person of 'Arab' descent, Saeed is defined by his body, his ethnicity and his religion, which are all considered to fall outside the normative framework of what it means to be 'Australian' in Springville. To 'be okay' at Springville High is to be a particular sort of raced, nationed, and religioned student.

Mr James' remarks regarding Saeed and his place in the Springville community speak both to and against belonging. While Saeed's peers are clearly prepared to use racist speech against Muslims in their reference to "towelheads", they are also prepared to defend Saeed's right to belong. In this sense, they have an investment in being both racist and non-racist, or as Raby (2004) argues, their discursive repertoire discloses the way "multiple positions on racism can be held concurrently" (p. 372). The students' defence of Saeed, as reported by Mr James illustrates the way they make insider/outsider distinctions between Muslims they know and Muslims they do not. This, in effect, tactically reframes racism to fit their friendship needs and shows how 
boundaries of tolerance and acceptance are strategic (Rizvi, 2009) and are framed politically to construct a social space that is both complex and nuanced.

In the following discussion, we continue to exemplify how teachers can inadvertently construct students in states of unbelonging. We also highlight how particular teaching practices can lead students to feelings of unbelonging. We then consider the implications for teacher education that might unsettle this discursive climate.

\section{Discourses of exclusion: Hanif}

In the next vignette we consider more explicitly the issue of teaching for belonging. We illustrate how teachers' knowledge of their students impacts their ability to respond in culturally appropriate ways to an increasingly diverse student population (Santoro, 2009). Delpit (1995) argues that "in order to teach you, I must know you" (p. 183). This argument is taken up in this analysis to investigate what Santoro claims is the importance of knowing one's students in order to promote socially just classroom practices (Santoro, 2009). The pedagogical knowledges and practices that are required of teachers to produce classroom environments conducive to the needs of students who sit outside the dominant cultural majority are thus explored in this vignette.

Table 2. Vignette Two: Part i. Physical Education lesson, Gundah High School Three Physical Education classes combine for a lesson in the hall attached to the school canteen. Lunch tables are pushed to the edge of the room to make a space for dancing the focus of today's lesson. The hall is spacious and is rimmed outside with trees on one side where the room overlooks an extensive plateau of rural landscape in the distance. Students stand in rows, a metre apart, facing the front of the room. On a sandy-coloured parquetry floor, students are instructed in the finer points of the 'Nutbush' dance by 
three teachers who demonstrate how the dance unfolds. The dance is practised over and over as the music plays on repeat. This is an 'individual' dance where no physical contact with other students is required, and students participate with varying degrees of enthusiasm. After 15 minutes or so of 'nutbushing', the teachers announce that it is time to move on to the 'bush' dance. At this point in the lesson, the Muslim students move off the dance floor and proceed to sit on chairs positioned at the side of the room. (Researcher Fieldnotes)

Table 3. Vignette Two: Part ii. Interview with Hanif, Gundah High School When Hanif was subsequently asked about the class by one of the authors, he responded:

You're not allowed to, like, touch girls [during Ramadan] ... At first my teachers didn't believe me ... She goes "No, you're dancing" ... So then [the teacher] said "Dance!" And I said "no, I'm fasting". And then she said "Okay, you can stay back then" [for detention]. But my other teacher he knows about it „,cause he's heard it at [another local school] ... and he said [explaining Hanif's reluctance to dance to the other teacher] "Oh no, they don't have to do it". So some teachers know and some teachers don't know.

Teaching practice that neither recognises nor accommodates religious difference is highlighted in the vignette above. The failure of the teacher to 'know' students and her assumption that all the learners will be able to, and willing to participate in the dance is troubling for a number of reasons. First, such a construction suggests that students' cultures are homogenous and that all learners can be treated the same, and can 
be expected to conform to the same 'norms'. Second, the teacher enacts an activity that is not available to all students and that becomes the means to disenfranchise some students from the learning experience and produce them in states of unbelonging. As Santoro (2009) argues: "teachers must know what is culturally relevant to their students and must recognise when existing curriculum fails to build on or acknowledge the cultural knowledge students bring to their learning" (p. 39). In this vignette, the teacher's failure to know the cultural values and beliefs of her Muslim students results in the students' exclusion.

The example reported above sits alongside further field observations at Gundah High School that highlight the significant role of 'looks' or racial appearance in teachers' failure to teach for belonging. In a second example of this, Hanif's Year Advisor was heard to say that because of the 'Whiteness' of the Afghan students' skin, “you wouldn’t even know" they were from another place. Such practices of racialization, where racial identity is read through markers on the body, position Hanif and the other Afghan students at the school as the culturally 'unmarked' peers of the White students. This comment is suggestive of a response to the students where 'fitting in' occurs naturally and unproblematically. In terms of teaching practice, there is a suggestion of 'sameness' between the Afghan and White-majority learner population. Simultaneously, against broader discourses circulating within the school, the Afghan students are positioned as distinct from the White host population - they are named as ethnic, Muslim and refugee students; naming practices that constitute the students outside of what it is to be recognised as a 'genuine' Australian student at Gundah High School. In both circumstances, the students can be understood to be caught in discourses of high visibility and/or invisibility that position them with unequal access to belonging. 
These examples of teacher-talk and practice illustrate the importance of teachers having complex knowledge of students. The findings reported here suggest that teachers can have limited or no understanding of the ethnicity, religion and culture of their students. Knowing students in complex ways involves teachers understanding the ethnic and cultural identities of their students and how minority students are different from, and similar to, majority students (Santoro, 2009).

\section{A pedagogy of belonging}

In this section, we put forward the notion of a 'pedagogy of belonging' as a starting point for disrupting practices of teaching that can lead to unbelonging. The findings of this study highlight the need for pedagogies that create all students in states of belonging. Such practices, we suggest, are necessary if students are to take up effective learner identities.

Pedagogies that take as their starting point students' situated knowledges have a long tradition in education. Paulo Freire's treatise that "the teacher's thinking is authenticated only by the authenticity of the students' thinking" $(1994$, p. 58) is popularly held, and has received subsequent expression in research and pedagogies concerned with issues of diversity (Youdell, 2011). Learners are active participants in the construction of knowledge and their lived experiences and prior knowledges need to be acknowledged and considered. In line with this thinking, we put forward the notion of engagement with students' situated knowledges as an important element in constructing a pedagogy of belonging.

As this study has shown, the community, with its inherent possibilities for close association and relationship, is an important site for delivering intercultural belonging. Wise (2005) argues against the traditional notion of communities as places where 
boundaries are always tightly guarded, as spaces that necessarily privilege exclusion and closure. She suggests, instead, that communities can be places where "hopeful gestures" and "recognition" can "create a mutual opening up to one another", where there is the "possibility of recognising the stranger" (p. 182). While persons are connected in layers of belonging to nation and to international contexts, they are, at the same time, significantly produced in local relations. To this end, Wise suggests that "an important relationship is that between the abstract and the concrete other" (p. 183). As illustrated in Saeed's story, this study reveals that persons are able to make distinctions between the concrete Other (the Muslim they know) and the abstract Other (an imagined community of Muslims whom they do not know and around whom suspicion is generated), where the abstract subject is connected in discourse to narratives of nation and national belonging. It is in the possibilities opened up by the local - by acts of knowing in the everyday - that potential for belonging is engendered in these unthreatening, situated encounters. While this article takes as its focus ethnic and religious diversity in the rural context, we propose the relevance of this examination not just for rural education, but for other situated spaces of knowing.

Taking up students' prior, situated knowledge of ethnic and cultural difference as a starting point for building students' knowledge of themselves and others is an important consideration in constructing a pedagogy of belonging. Such action is predicated on teachers having complex knowledges of their students. However, as Santoro (2009) argues, in order for teachers to develop rich and nuanced understandings of students of ethnic difference they must also know themselves as encultured; they must understand how their pedagogies are shaped by their own ethnicity and cultural beliefs and practices. Knowledge of others and knowledge of self "are mutually 
constitutive, as each builds upon, and is dependent on the other to make meaning (Santoro, 2009, p.41)".

The teachers in the study reported here appear to be unaware of the exclusionary effects of discourse that constructs student identity in deficit terms, and of treating all students as if they are the same. To this end, an important next step in the production of a pedagogy of belonging is replacing pedagogies that privilege a false homogeneity with pedagogies that are responsive to heterogeneity. This is necessary in order to undo a schooling situation that privileges those students who come to school already equipped with identities that 'fit' within existing normative structures of education. Within this framework, students should be regarded as individuated learners, rather than as 'refugees', 'Muslims' or 'ethnics', for example; naming practices that are constitutive of essential subjecthood and that have the potential to trap students in discourses and practices of exclusion. Recognition of the ways in which students can be ensnared in discourses of high visibility but low levels of belonging are required in order to enact a more socially just pedagogy. Critical recognition is needed of the unequal access children have to the dominant culture, and engagement is needed with pedagogies that question and challenge the very prevalence of this culture.

\section{Conclusion}

Understanding how states of belonging and unbelonging in schools are established is to discern how the identities of students - around categories such as ethnicity, culture and religion - are positioned, in part, through teacher knowledges and practices. To this end, the importance to quality schooling of teachers 'knowledge of students' is necessary. More emphasis needs to be given, however, to the importance of teachers having complex knowledge of students in realizing culturally responsive 
classrooms; a practice that is inevitably entwined with teachers' knowledge of themselves as ethnic and encultured. This paper also suggests the importance of students' situated knowledges as an often overlooked, but important site for building intercultural understanding and competence. Engaging and building students' local ways of understanding ethnic and religious difference as a means to unpack the broader discourses upon which these narratives are built is an important discursive project. This article suggests that this teaching be coupled with practice that troubles deficit constructions of student identity.

The challenge for teacher education is to develop skills in initial teacher education students that prepare them to better challenge existing inequalities in schools and to take up a pedagogy of belonging. There is a need to develop specific strategies for teachers to use in schools and classrooms, as well as a need to understand the points of frailty and resistance of such strategies. Situated analyses of classroom practice, where teacher educators and teachers take up understandings of power and knowledge of the kind offered in this study to explore ways to trouble educational inclusions and exclusions in everyday practices of schooling would appear to be a way forward in developing detailed understandings of the effectiveness of discursive pedagogies in schooling. Such an approach has importance for thinking through implications for teacher knowledge, student knowledge, curricula and pedagogy, as well as future spaces of research in identity politics. In working with teachers to pursue socially just schooling, important accounts of how a pedagogy of belonging might work in practice, can emerge. The tactics and day-to-day practices that might best be taken up to unsettle schooling inequalities can be considered, as well as their success in interrupting normative regimes of understanding. 


\section{References}

Allard, A., \& Santoro, N. (2006), Troubling identities: teacher education students' constructions of class and ethnicity. Cambridge Journal of Education, 36(1), pp. 115-129.

Ang, I. (2001). On not speaking Chinese: Living between Asia and the West. London: Routledge.

Arber, R. (2008b). Race, ethnicity and education in globalised times. Dordrecht, The Netherlands: Springer.

Butler, J. (1997). Excitable speech: A politics of the performative. New York: Routledge.

de Certeau, M. (1984). The practice of everyday life. Berkeley: University of California Press.

Delpit, L. (1995). Other People's Children: Cultural Conflict in the Classroom (2 ${ }^{\text {nd }}$ edn.). New York: Routledge.

Edgeworth, K. (2014). Black bodies, White spaces: Disturbing pedagogies of unbelonging. Critical Studies in Education.

DOI:10.1080/17508487.2014.956133

Freire, P. (1994). Pedagogy of the oppressed. New York: Continuum.

Goldstein, T. (2008). Multiple commitments and ethical dilemmas in performed ethnography. Educational Insights, 12(2), 1-19.

Hage, G. (1998). White nation: Fantasies of white supremacy in a multicultural society. Sydney: Pluto Press.

Inglis, C. (2009). Multicultural education in Australia: Two generations of evolution. In J. A. Banks (Ed.), The Routledge international companion to multicultural education (pp. 109-120). New York: Routledge.

Keddie, A. (2012a). Educating for diversity and social justice. New York: Routledge.

Keddie, A. (2012b). Refugee education and justice issues of representation, redistribution and recognition. Cambridge Journal of Education, 42(2), 197212.

Lander, V. (2011). Race, culture and all that: An exploration of the perspectives of White secondary student teachers about race equality issues in their initial teacher education. Race, Ethnicity and Education, 14(3), 351-364.

Martino, W. \& Rezai-Rashti, G. M. (2008). The politics of veiling, gender and the Muslim subject: On the limits and possibilities of anti-racist education in the 
aftermath of September 11. Discourse: Studies in the Cultural Politics of Education, 29(3), 417-431.

Mills, C., \& Ballantyne, J. (2010). Pre-service teachers' dispositions towards diversity: Arguing for a developmental hierarchy of change. Teaching and Teacher Education, 26(3), 447-454.

Noble, G., \& Poynting, S. (2010). White lines: The intercultural politics of everyday movement in social spaces. Journal of Intercultural Studies, 31(5), 489-505.

Pain, R., \& Smith, S. J. (2008). Fear: Critical geopolitics and everyday life. In R. Pain \& S. J Smith (Eds.), Fear: Critical geopolitics and everyday life (pp. 1-19). Aldershot, UK: Ashgate.

Raby, R. (2004). 'There's no racism at my school, it's just joking around': ramifications for anti-racist education. Race Ethnicity and Education, 7(4), 367-383.

Rizvi, F. (2009). Review symposium. British Journal of Sociology of Education, 30(3), 359-371.

Santoro, N. (2009). Teaching in culturally diverse contexts: What knowledge about 'self' and 'others' do teachers need? Journal of Education for Teaching. 35(3), $33-45$.

Santoro, N. (2013) "If I'm going to teach about the world, I need to know the world": Developing Australian preservice teachers' intercultural competence through international trips. Race, Ethnicity and Education. DOI: 10.1080/13613324.2013.832938

Sibley, D. (2006). Inclusions/exclusions in rural space. In P. Cloke, T. Marsden, \& P. Mooney (Eds.), Handbook of rural studies (pp. 401-410). London: Sage.

Wise, A. (2005). Hope and belonging in a multicultural suburb. Journal of Intercultural Studies, 26(1-2), 171-186.

Youdell, D. (2006). Impossible bodies, impossible selves: Exclusions and student subjectivities. Dordrecht, The Netherlands: Springer.

Youdell, D. (2011). School trouble: Identity, power and politics in education. London: Routledge. 